ARTICLE

DOI: $10.1038 / s 41467-018-07525-y$

\title{
Cobalt-catalyzed difluoroalkylation of tertiary aryl ketones for facile synthesis of quaternary alkyl difluorides
}

Chao Li (i) ${ }^{1}$, Yi-Xuan Cao ${ }^{1}$, Rui Wang ${ }^{1}$, Yi-Ning Wang ${ }^{1}$, Quan Lan $^{1} \&$ Xi-Sheng Wang $\mathbb{D}^{1}$

The selective incorporation of gem-difluoroalkyl groups into biologically active molecules has long been used as an efficient strategy for drug design and discovery. However, the catalytic $\mathrm{C}\left(\mathrm{sp}^{3}\right)-\mathrm{CF}_{2}$ bond-forming cross-coupling reaction for selective incorporation of difluoromethylene group into diverse alkyl chains, especially more sterically demanding secondary and tertiary functionalized alkanes, still remains as a major challenge. Herein, we describe a cobalt-catalyzed difluoroalkylation of tertiary aryl ketones for facile synthesis of quaternary alkyl difluorides, which exhibited high efficiency, broad scope and mild conditions. The synthetic utility of this method is demonstrated by late-stage difluoroalkylation of donepezil, a well-known acetylcholinesterase inhibitor used to treat the Alzheimer's disease. Preliminary mechanistic investigations indicate that a difluoroalkyl radical is involved in a $\mathrm{Co}(\mathrm{I}) / \mathrm{Co}(\mathrm{III})$ catalytic cycle. This cobalt-catalyzed fluoroalkylation thus offers insights into an efficient way for the synthesis of fluoroalkylated bioactive molecules for drug discovery.

\footnotetext{
${ }^{1}$ Hefei National Laboratory for Physical Sciences at the Microscale and Department of Chemistry, Center for Excellence in Molecular Synthesis of CAS, University of Science and Technology of China, Hefei, Anhui 230026, China. These authors contributed equally: Chao Li, Yi-Xuan Cao. Correspondence and requests for materials should be addressed to X.-S.W. (email: xswang77@ustc.edu.cn)
} 
$\mathrm{T}$ he wide use of fluorinated compounds in pharmaceuticals, agrochemicals, and advanced materials vigorously propelled the development of efficient methods for the incorporation of fluorine or fluorinated moieties into organic molecules ${ }^{1-3}$. In the past decades, transition-metal-catalyzed fluoroalkylation has emerged as an efficient and convenient alternative approach to direct fluorination for facile synthesis of fluorine-containing organic compounds ${ }^{4-11}$. Among all welldeveloped active catalysts, palladium- ${ }^{12-19}$ and coppercatalyzed $^{20-29}$ or -mediated ${ }^{30-33}$ fluoroalkylation reactions have long proved to be the most useful and reliable tools for effective synthesis of fluoroalkylated molecules. Recently, the earth-abundant, inexpensive, and environmentally friendly first-row transition metals, including $\mathrm{Ni}, \mathrm{Fe}$, and $\mathrm{Co}$, have attracted increasing attention on $\mathrm{C}-\mathrm{C}$ bond-forming reactions due to their different and complementary catalytic reactivities to late and noble transition metals $s^{34-36}$. Whereas nickel ${ }^{37-44}$ and iron ${ }^{45-48}$ have already been demonstrated as efficient catalysts for such fluoroalkylation reactions, cobalt-catalyzed fluoroalkylation has been less studied and remained as a major challenge. To the best of our knowledge, the only two examples on cobalt-catalyzed ${ }^{49,50}$ fluoroalkylation were limited to aryl zinc and magnesium nucleophiles, whereas the cross-coupling of alkyl species for construction of fluorinated alkanes still remained as an issue left to be solved so far.

The selective incorporation of gem-difluoroalkyl groups into drug-like molecules has long been known as a powerful strategy for drug design and discovery, as their structural diversity and the ability to modulate the electronic properties of parent molecules ${ }^{51-}$ 54 . To date, a number of difluoroalkylation reactions have been well-developed into the construction of $\mathrm{C}\left(\mathrm{sp}^{2}\right.$ or $\left.\mathrm{sp}\right)-\mathrm{CF}_{2} \mathrm{R}$ bonds, in which fluorine atoms were normally oriented at relatively unique benzyl, allyl, and propargyl positions ${ }^{12-20,23-28,46-48,55-57}$. In contrast, the catalytic $\mathrm{C}\left(\mathrm{sp}^{3}\right)-\mathrm{CF}_{2}$ bond-forming reaction for selective incorporation of difluoromethylene group into the alkyl chain at any special position, is still scarce and remains as an unsolved problem ${ }^{58}$. The only example on transition-metal catalyzed crosscoupling between alkyl substrates and difluoroalkylating reagents was just reported by Zhang and coworkers ${ }^{59}$; however, the alkylzinc reagents in this transformation were still limited to primary alkyl compounds, probably due to the lack of reactivity with more sterically demanding secondary and tertiary alkylating reagents (Fig. 1a) ${ }^{60}$.

Different from palladium or nickel catalyzed alkylations, the decomposition of alkyl-cobalt intermediates via $\beta$-hydrogen elimination is really not a limitation ${ }^{34}$. Whereas cobalt catalysis has demonstrated especially efficient for coupling of alkyl halides, we conceived the unique catalytic characteristics of cobalt could enable the facile constuction of $\mathrm{C}\left(\mathrm{sp}^{3}\right)-\mathrm{CF}_{2}$ bonds. Herein, we report a cobalt-catalyzed difluoroalkylation of tertiary aryl ketones with fluoroalkyl bromides (Fig. 1b). This approach has demonstrated high-catalytic reactivity and broad substrate scope, thus enabling the late-stage fluoroalkylation of biologically active molecules. This strategy offers a solution for facile synthesis of quaternary alkyl difluorides, and provides an efficient way for the synthesis of fluoroalkylated bioactive molecules for drug discovery.

\section{Results}

Optimization of the co-catalyzed cross-coupling. Our study commenced with 2-phenyl-3,4-dihydronaphthalen-1(2H)-one 1a as the pilot substrate and bromodifluoroacetate $\mathbf{2} \mathbf{a}$ as the coupling partner in the presence of catalytic amount of $\mathrm{CoBr}_{2}(10 \mathrm{~mol} \%)$ and $\mathrm{dppBz}(10 \mathrm{~mol} \%)$ in THF at $-10^{\circ} \mathrm{C}$. Not surprisingly, only trace amount of the desired product 3a was observed when a

Previous work: Ni-catalyzed difluoropropargylation of $1^{\circ}$ alkylzinc reagents.

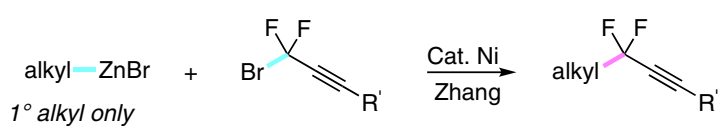

b

This work: Co-catalyzed difluoroalkylation of tertiary aryl ketones.

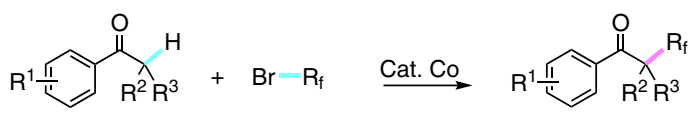

Fig. 1 Transition-metal-catalyzed cross-coupling for facile synthesis of difluoroalkylated alkanes. a Ni-catalyzed difluoropropargylation of $1^{\circ}$ alkylzinc reagents. b Co-catalyzed difluoroalkylation of tertiary aryl ketones

${ }^{t} \mathrm{BuOK}$ was used as the base (Table 1, entry 1 ). To our delight, $30 \%$ yield of $\mathbf{3 a}$ was isolated when zinc metal (0.5 equiv) was added as the key reductant to generate the active cobalt catalyst (Table 1, entry 2$)^{63}$. Further investigation indicated that manganese was not the suitable reductant (Table 1, entry 3), and reducing the amount of zinc resulted in a decline in yield $(17 \%$, Table 1, entry 4). To further improve the yield, a careful examination of base was carried out when 0.5 equiv of zinc was added. Whereas inorganic bases gave almost none of the product $\mathbf{3 a}$, organic bases, including KHMDS and LiHMDS showed good reactivity, and LDA proved as the optimal choice with $90 \%$ yield (Table 1, entries 5-7). Different kinds of nitrogen, phosphine, and carbene ligands were next studied, but all gave obviously lower yields or even none of 3a (Supplementary Table 3). Additionally, careful screening of solvents and cobalt sources indicated THF and $\mathrm{CoBr}_{2}$ were still the best choices (Table 1, entries 8-12 and Supplementary Tables 2 and 6). The reaction temperature was also investigated, which demonstrated that lower temperature even to $-30^{\circ} \mathrm{C}$ still gave the same excellent yield, but increasing higher temperature $\left(0^{\circ} \mathrm{C}\right)$ resulted in a significant reduction in yield (Table 1, entries 13-14). Finally, control experiments confirmed that almost none of the desired product 3a was detected in the absence of cobalt catalyst (Table 1, entry 15).

Scope of the co-catalyzed cross-coupling. With these optimized condition in hand, various aryl ketone $\mathbf{1}$ were next tested in this catalytic fluoroalkylation system. As shown in Fig. 2, a variety of cyclic and acyclic aryl ketones were difluoroalkylated successfully, furnishing the desired products $\mathbf{3}$ with difluoroalkylated quaternary carbon centers in good to excellent yields. To our satisfaction, the examination of $\alpha$-substituents $\left(\mathrm{R}^{1}\right)$ of cyclic aryl ketones showed that not only a great number of substituted aryl groups, but also various alkyl groups like $\mathrm{Me}(\mathbf{3 b}), n-\mathrm{Bu}(\mathbf{3 c}), \mathrm{Bn}$ (3d), and $i-\operatorname{Pr}(\mathbf{3 e})$, were smoothly difluoroalkylated with good yields. It should be noted that five- or six-membered carbon rings and even O-containing chromanone were well tolerated in this reaction (3a-3r). Indeed, cyclic and acyclic aryl ketones installed with both electron-donating groups, including $\mathrm{Me}(\mathbf{3 f}, \mathbf{3 q}, \mathbf{3 t}, \mathbf{3 \mathbf { u }})$, $\mathrm{MeO}(\mathbf{3 k - 3 m}, 3 \mathbf{v}-\mathbf{3} \times, 3 \mathbf{a f}, 3 \mathbf{a h}), \mathrm{Me}_{2} \mathrm{~N}$ (3ag), and electronwithdrawing groups, such as $\mathrm{F}$ (3i, $\mathbf{3 a d}, \mathbf{3 a f}), \mathrm{Cl}(\mathbf{3 g}, \mathbf{3} \mathbf{j}, \mathbf{3 r}, \mathbf{3 a e})$, and $\mathrm{Br}(\mathbf{3 h}, \mathbf{3 n})$, on the phenyl rings were fluoroalkylated effectively to give the desired products with acceptable yields in our catalytic system. Remarkably, both cyclic and acyclic aryl ketones containing $\mathrm{F}$ (3i, 3ad, 3af), $\mathrm{Cl}$ (3g, 3j, 3r, 3ae), $\mathrm{Br}$ (3h, 3n) were also suitable coupling partners, which clearly demonstrated good functional group tolerance of our method and offered the synthetic potential for further elaboration by transition-metalcatalyzed coupling reactions. Gratifyingly, acyclic aryl ketones bearing two alkyl groups at the $\alpha$-position (3aj) were well tolerated in our reaction. In addition, aryl ketones containing primary 
Table 1 Cobalt-catalyzed difluoroalkylation: optimization of conditions ${ }^{a}$

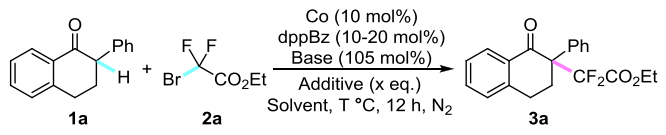

\begin{tabular}{|c|c|c|c|c|}
\hline Entry & Co source & Base & Addi./equiv & Yield $(\%)^{b}$ \\
\hline 1 & $\mathrm{CoBr}_{2}$ & ${ }^{t} \mathrm{BuOK}$ & - & trace \\
\hline 2 & $\mathrm{CoBr}_{2}$ & ${ }^{t} \mathrm{BuOK}$ & $\mathrm{Zn}(0.5)$ & 30 \\
\hline 3 & $\mathrm{CoBr}_{2}$ & ${ }^{t} \mathrm{BuOK}$ & $\operatorname{Mn}(0.5)$ & trace \\
\hline 4 & $\mathrm{CoBr}_{2}$ & ${ }^{t} \mathrm{BuOK}$ & $\mathrm{Zn}(0.3)$ & 17 \\
\hline 5 & $\mathrm{CoBr}_{2}$ & KHMDS & $\mathrm{Zn}(0.5)$ & 73 \\
\hline 6 & $\mathrm{CoBr}_{2}$ & LiHMDS & $\mathrm{Zn}(0.5)$ & 77 \\
\hline 7 & $\mathrm{CoBr}_{2}$ & LDA & $\mathrm{Zn}(0.5)$ & 90 \\
\hline 8 & $\mathrm{CoI}_{2}$ & LDA & $\mathrm{Zn}(0.5)$ & 83 \\
\hline 9 & $\mathrm{CoCl}_{2} \bullet$ dppe & LDA & $\mathrm{Zn}(0.5)$ & 56 \\
\hline 10 & $\mathrm{Co}(\mathrm{OAc})_{2} \bullet 4 \mathrm{H}_{2} \mathrm{O}$ & LDA & $\mathrm{Zn}(0.5)$ & 30 \\
\hline 11 & $\mathrm{Co}(\mathrm{acac})_{2}$ & LDA & $\mathrm{Zn}(0.5)$ & 42 \\
\hline $12^{\mathrm{c}}$ & $\mathrm{CoBr}_{2}$ & LDA & $\mathrm{Zn}(0.5)$ & 50 \\
\hline $13^{\mathrm{d}}$ & $\mathrm{CoBr}_{2}$ & LDA & $\mathrm{Zn}(0.5)$ & 90 \\
\hline $14^{\mathrm{e}}$ & $\mathrm{CoBr}_{2}$ & LDA & $\mathrm{Zn}(0.5)$ & 53 \\
\hline 15 & - & LDA & $\mathrm{Zn}(0.5)$ & trace \\
\hline
\end{tabular}

$\mathrm{dppBz}=1,2$-bis(diphenylphosphino)benzene

aReaction conditions: 1a $\left(0.2 \mathrm{mmol}, 1.0\right.$ equiv), 2a (3.0 equiv), [Co] (10 mol\%), dppBz (10 mol\%), base (105 mol\%), Zn (0.5 equiv), solvent (2.0 mL), $-10{ }^{\circ} \mathrm{C}, 12 \mathrm{~h}, \mathrm{~N}_{2}$ bYields of the isolated products given

'Dioxane was used as solvent

$\mathrm{d} T=-30^{\circ} \mathrm{C}$

${ }^{\mathrm{e}} \mathrm{T}=0^{\circ} \mathrm{C}$

and secondary $\mathrm{\alpha}-\mathrm{C}-\mathrm{H}$ bonds had also been investigated in this catalytic system. While no reaction was observed with $\mathrm{PhCOCH}_{3}$, $\mathrm{PhCOCH}_{2} \mathrm{R} \quad(\mathrm{R}=\mathrm{Me}, \mathrm{Ph})$ afforded tetrasubstituted monofluoroalkenes 8 and $\mathbf{9}$ in $31 \%$ and $41 \%$ yield, respectively. In contrast, cyclic aryl ketone furnished a 3,3-difluorofuran-2-one derivative 10 accordingly (Supplementary Figure 186).

To further demonstrate the scope of fluoroalkylating reagents, various kinds of difluoroalkyl bromides were examined in this catalytic system. Not surprisingly, as the analogues with similar reactivity to difluoroacetate $\mathbf{2 a}$, bromodifluoroacetamides were also compatible with this reaction. Different acetamides, including acyclic diethyl amine, cyclic piperidine, morpholine, and piperazine, could be well tolerated in this transformation with acceptable yields. Additionally, the difluoromethylated arene (3al) and heteroarene (3ak) could be smoothly coupled to the aryl ketones using this method. Furthermore, the scope of difluoroalkylating reagents had been demonstrated via a diversity of cross-coupling reactions between different kinds of cyclic or acyclic aryl ketones and difluoroalkyl bromides. It is known that the gem-difluoromethyl group $\left(\mathrm{CF}_{2}\right)$ serves widely as a key motif to improve the biological activity of target drug molecules ${ }^{53,54}$, and this method thus demonstrates its application prospect to access diverse difluoroalkylated aryl ketones for drug screen.

Owing to the mild conditions and good functional group tolerance demonstrated in this catalytic system, the synthetic potential of this method was next elucidated via late-stage modification of biologically active molecules with structural diversity. Indeed, donepezil, a well-known acetylcholinesterase inhibitor used to treat the Alzheimer's disease ${ }^{61}$, could be difluoroalkylated smoothly with good yields. As shown in Fig. 3, different functional groups, such as ester (5a), benzo[d]oxazole $(5 \mathbf{b})$, and arene $(5 \mathbf{c})$, in the fluoroalkylating reagents were all well compatible with this catalytic transformation. As an efficient and expedient tactic for the construction of fluorine-containing analogues, these late-stage fluoroalkylations of complex molecules could offer a useful strategy to modify the lead compounds in drug development.

Mechanistic studies. To gain some insights into this cobaltcatalyzed difluoroalkylation, a series of control experiments were next performed. Firstly, the subjection of $\beta$-piene into the reaction could afford the cycle-opening product 7 in $12 \%$ yield along with $35 \%$ yield of the desired difluoroalkylated product 3s (Fig. 4a). 


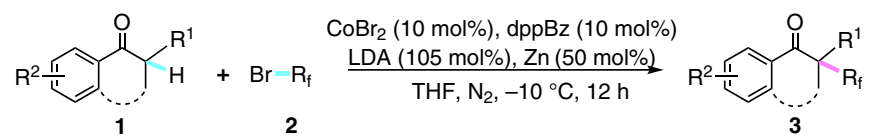

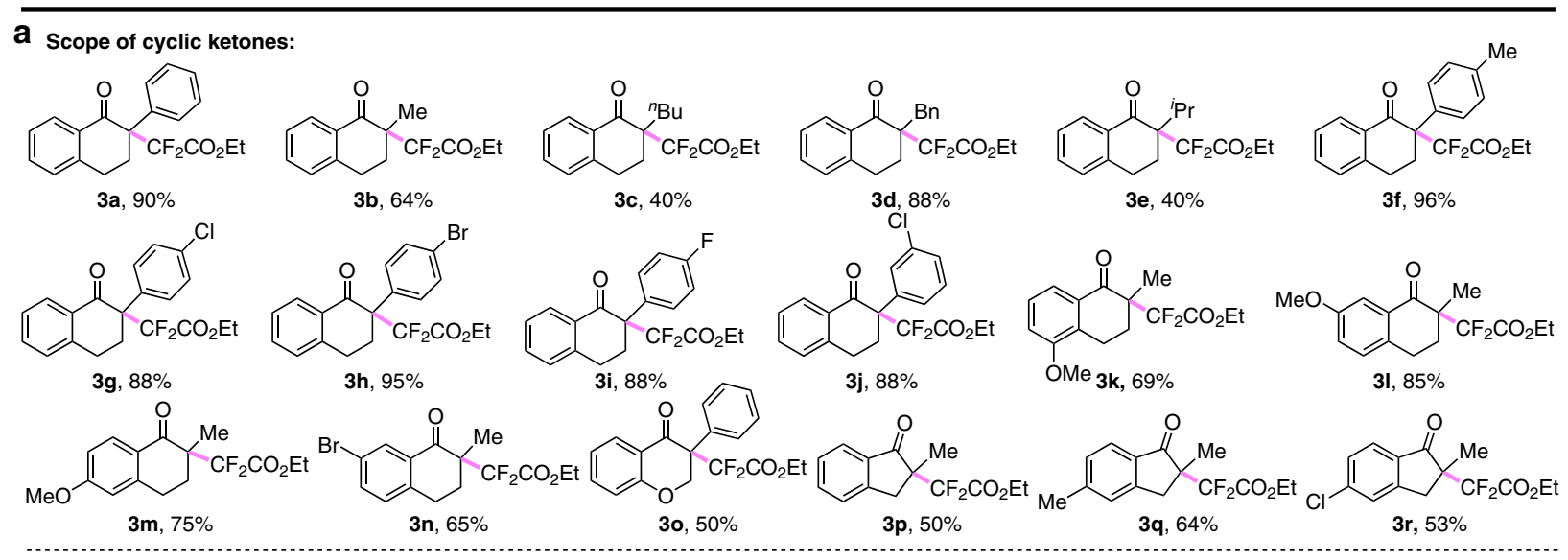

b scope of acyclic ketones:
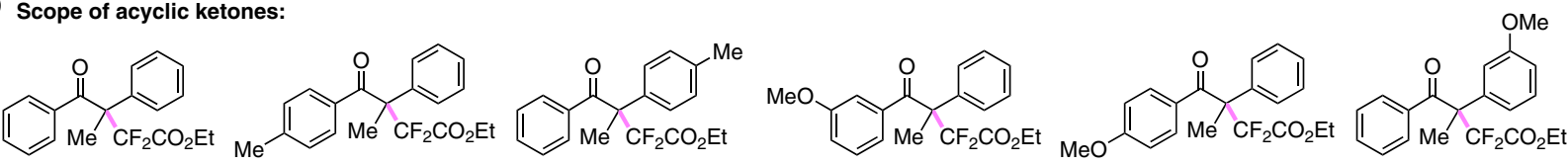

3s, $80 \%$

3t, $75 \%$

$3 u, 65 \%$

$3 v, 77 \%$

$3 w, 85 \%$

$3 \mathbf{x}, 76 \%$
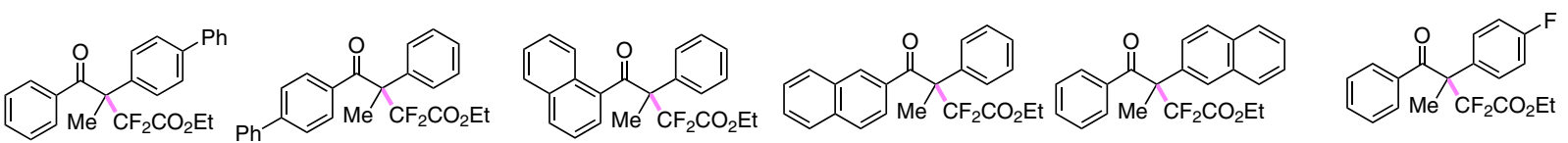

3y, $76 \%$

3z, $65 \%$

3aa, $71 \%$

3ab, $60 \%$

3ac, $65 \%$

3ad, $63 \%$<smiles>CCOC(=O)C(C)(c1ccc(Cl)cc1)C(C)(C(=O)c1ccccc1)c1ccccc1</smiles>

3ae, $70 \%$<smiles>CCOC(=O)C(C)(C(=O)c1ccc(OC)cc1)C(C)(C(=O)c1ccc(F)cc1)c1ccc(F)cc1</smiles>

3af, $74 \%$

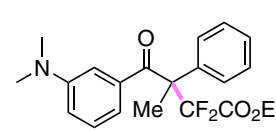

3ag, $71 \%$

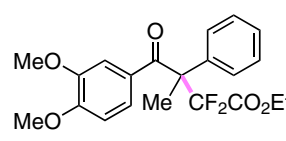

3ah, $65 \%$

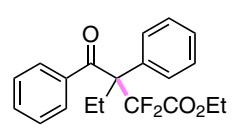

3ai, $40 \%$

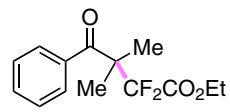

3aj, $41 \%^{\mathrm{a}}$

\section{Scope of difluoroalkylating reagents:}<smiles>NC1(C(F)(F)c2nc3ccccc3o2)Cc2ccccc2C1=O</smiles>

3ak, $57 \%$<smiles>Cc1ccc(C2(C(F)(F)C(=O)N3CCCCC3)CCc3ccccc3C2=O)cc1</smiles>

3aq, $75 \%$

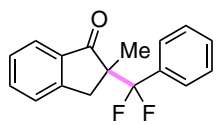

3al, $60 \%$<smiles>CCN(CC)C(=O)C(F)(F)C1(F)Cc2ccccc2C1=O</smiles>

3am, 53\%<smiles>Cc1ccc(C2(C(=O)C(=O)N3CCOCC3)CCc3ccccc3C2=O)cc1</smiles><smiles>CCN(CC)C(=O)C(F)(F)C1(c2ccc(C)cc2)C(=O)Cc2ccccc2C1=O</smiles>

3as, $81 \%$<smiles>[M]C1(C(=O)C(=O)N2CC[NH+](c3ccccc3)CC2)Cc2ccccc2C1=O</smiles>

3an, $50 \%$<smiles>O=C(N1CCCCC1)C(F)(Br)C1(F)Cc2ccccc2C1=O</smiles>

3ao, $80 \%$<smiles>CCN(CC)C(=O)C(F)(Br)C1(F)CCc2ccccc2C1=O</smiles>

3ap, $78 \%$<smiles>O=C(O)C(F)(C(=O)N1CCOCC1)C1(c2ccc(F)cc2)CCc2ccccc2C1=O</smiles>

3at, $83 \%$<smiles>CCN(CC)C(=O)C(F)(F)C1(c2ccc(F)cc2)CCc2ccccc2C1=O</smiles>

3au, $83 \%$<smiles>O=C1c2ccccc2CC(F)(C(F)(F)C(=O)N2CCCCC2)C1c1ccc(F)cc1</smiles>

3av, $77 \%$

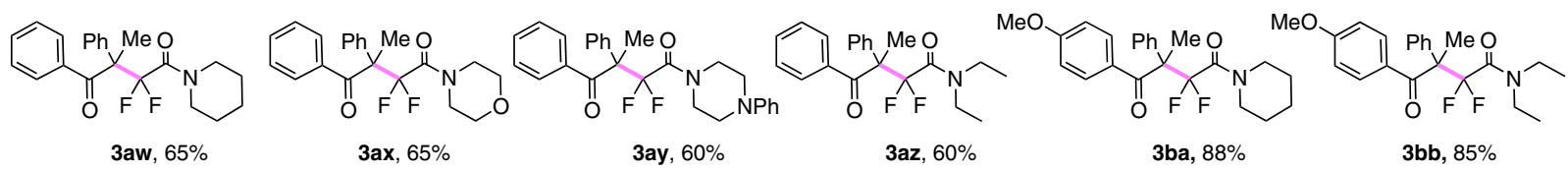

Fig. 2 Cobalt-catalyzed difluoroalkylation of aryl ketones. a Scope of cyclic ketones. b Scope of acyclic ketones. c Scope of difluoroalkylating reagents. Conditions: 1 (0.2 mmol, 1.0 equiv), 2 (3.0 equiv), $\mathrm{CoBr}_{2}(10 \mathrm{~mol} \%), \mathrm{dppBz}(10 \mathrm{~mol} \%), \mathrm{LDA}(105 \mathrm{~mol} \%), \mathrm{Zn}(0.5 \mathrm{equiv}), \mathrm{THF}(2.0 \mathrm{~mL}),-10{ }^{\circ} \mathrm{C}, 12 \mathrm{~h}, \mathrm{under}$ $\mathrm{N}_{2}$ atmosphere. ${ }^{\mathrm{a} C o n d i t i o n s: ~} 20 \mathrm{~mol} \%$ of $\mathrm{CoBr}_{2}$ and 20 mol\% of dppBz were used. dppBz = 1,2-bis(diphenylphosphino)benzene

This result indicated that a difluoroalkyl radical was in situ generated in the catalytic cycle. Considering the key role of zinc metal as a reductant for generation of active cobalt species, to understand the catalytically active species in this transformation, $\mathrm{Co}(\mathrm{I}) \mathrm{Cl}\left(\mathrm{PPh}_{3}\right)_{3}$ had been synthesized and subjected into the reaction ${ }^{63}$. It was found that the addition of zinc metal or not into the standard catalytic conditions had no effect to this transformation (Fig. $4 \mathrm{~b}$ ), giving the desired product $3 \mathrm{~s}$ in almost the same yield $(70 \%$ and $71 \%)$. Whereas zinc metal showed indeed not a strong enough reductant to access $\mathrm{Co}(0)$ species $^{62}$, these results clearly revealed that $\mathrm{Co}(\mathrm{I})$ was the productive catalyst. To further investigate the evidence of generation of the difluoroalkyl radical, $\beta$-piene 6 was tested as a radical clock with different cobalt catalysts. As shown in Fig. 4c, the subjection of 1 equiv of $\mathrm{Co}(\mathrm{II}) \mathrm{Br}_{2} /$ $\mathrm{dppBz}$ and zinc were added together into the reaction affording the radical-scavenging product 7 , whereas the omission of zinc 


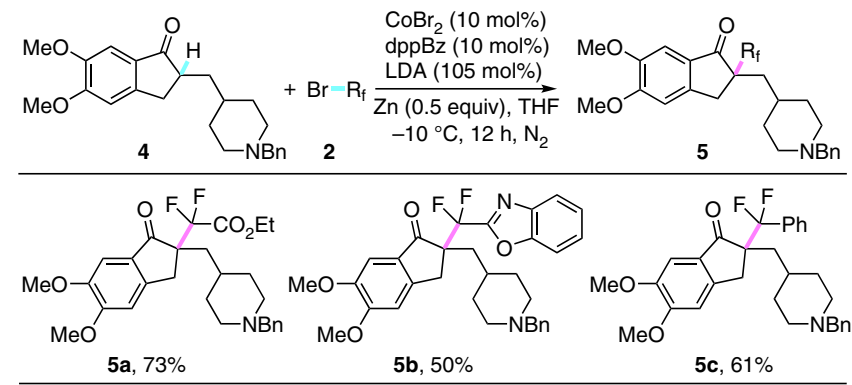

Fig. 3 Late-stage difluoroalkylation of biologically active molecules. Conditions: 4 (0.2 mmol, 1.0 equiv), 2 (3.0 equiv), $\mathrm{CoBr}_{2}$ (10 mol\%), dppBz (10 mol\%), LDA (105 mol\%), Zn (0.5 equiv), THF $(2.0 \mathrm{~mL}),-10{ }^{\circ} \mathrm{C}, 12 \mathrm{~h}$, under $\mathrm{N}_{2}$ atmosphere. $\mathrm{dppBz}=1,2$-bis(diphenylphosphino)benzene

a<smiles>C=C(C)C1CC=C(CCC(C)=O)CC1</smiles>

b

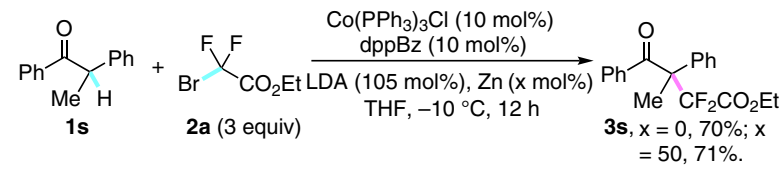

C

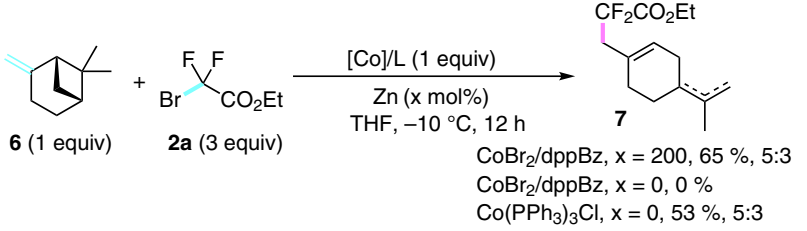

d

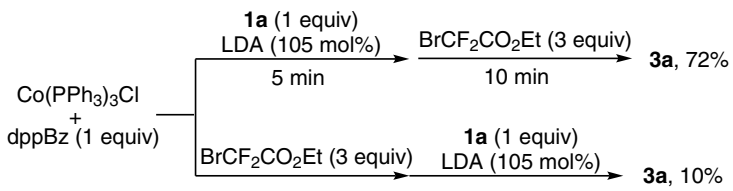

Fig. 4 Mechanistic studies. a Radical trapping experiment with $\beta$-piene. b Control experiments using Cobalt(I) complex. c Studies on generation of the difluoroalkyl radical. $\mathbf{d}$ Determination of the sequence of transmetallation and activation of fluoroalkyl bromide

furnished none of 7. Moreover, 1 equiv of premade $\mathrm{Co}(\mathrm{I}) \mathrm{Cl}$ $\left(\mathrm{PPh}_{3}\right)_{3}$ could give almost the same result as the combination of $\mathrm{Co}(\mathrm{II})$ and zinc used in the reaction system (Fig. 4c). All these results implied that the difluoroalkyl radical was generated by single-electron oxidation of $\mathrm{Co}(\mathrm{I})$ with difluoroalkyl bromide $\mathbf{2 a}$, and zinc served as an efficient reductant to reduce Co(II) to active $\mathrm{Co}(\mathrm{I})$ species $^{62}$. The in-situ reductive process mentioned not only existed in our system, but also has been reported before ${ }^{63}$. Furthermore, sequential addition of a mixture of $\mathbf{1 a}$ ( 1 equiv)/LDA (1 equiv), and then fluoroalkylating reagent $2 \mathrm{a}$ ( 3 equiv) gave a comparable yield in $72 \%$, but the reverse order of addition with the same reagents gave only $10 \%$ yield of the desired product $3 \mathrm{~s}$ (Fig. 4d). These results indicated the transmetallation step should occur before the activation of fluoroalkyl bromide.

Based on all of these results and the previous reports ${ }^{64-66}$, a proposed mechanism of $\mathrm{Co}(\mathrm{I})$ initiated cross-coupling was described in Fig. 5. First of all, reduction of $\mathrm{Co}(\mathrm{II})$ by zinc metal afforded the catalytically active $\mathrm{Co}(\mathrm{I})$ species $\mathbf{A}$ to start the cycle $^{66}$. Transmetallation between $\mathrm{Co}(\mathrm{I}) \mathrm{A}$ and enol anion B,

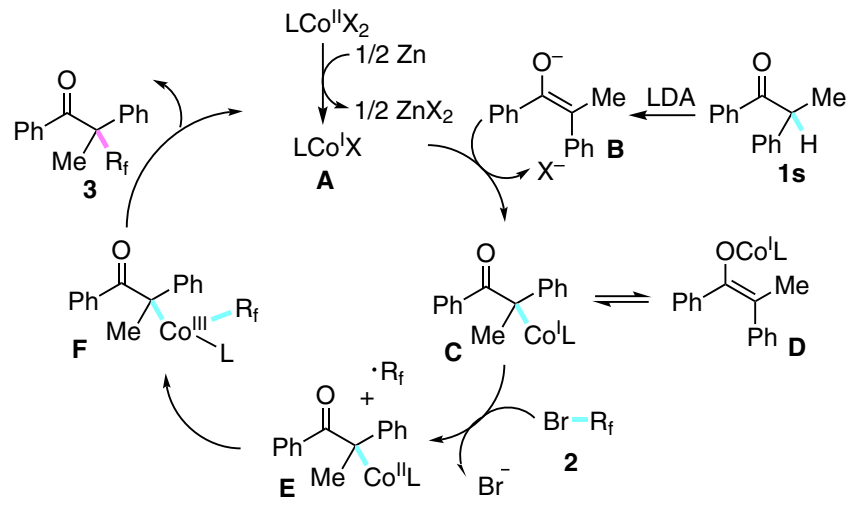

Fig. 5 Proposed mechanism. The possible reaction pathway based on our studies and the previous literatures

which was in situ generated with the assistance of LDA, afforded the corresponding $\mathrm{Co}(\mathrm{I})$ complex $\mathbf{C}$ and $\mathbf{D}$. A single electron oxidation of $\mathrm{Co}(\mathrm{I}) \mathrm{C}$ by fluoroalkylating reagent 2 generated the corresponding radical and $\mathrm{Co}(\mathrm{II})$ species, which was further transformed to $\mathrm{Co}(\mathrm{III})$ intermediate $\mathbf{F}$ after the following radical oxidation. At last, the reductive elimination of $\mathbf{F}$ furnished the final product 3 and regenerated $\mathrm{Co}(\mathrm{I})$ species to enter the next catalytic circle.

\section{Discussion}

In summary, we have developed a difluoroalkylation of tertiary $\mathrm{C}-\mathrm{H}$ bonds through cobalt-catalyzed cross-coupling between aryl ketones and fluoroalkyl bromides. Mechanistic investigations indicated this $\mathrm{C}-\mathrm{H}$ fluoroalkylation proceeds via a $\mathrm{Co}(\mathrm{I}) / \mathrm{Co}(\mathrm{III})$ catalytic cycle involving an in situ generated difluoroalkyl radical. This method has demonstrated mild conditions, broad substrate scope, and thus enabled the late-stage difluoroalkylation of complex molecules. This strategy will offer a solution for facile synthesis of quaternary alkyl difluorides. Further application of this method to fluorine-containing modification of complex biologically active molecules is still underway in our laboratory.

\section{Methods}

General procedure for the cobalt-catalyzed cross-coupling. To a $50 \mathrm{~mL}$ of Schlenk tube was added aryl ketone 1 ( 1.0 equiv, $0.2 \mathrm{mmol}$ ), $\mathrm{CoBr}_{2}(10 \mathrm{~mol} \%, 0.02$ $\mathrm{mmol}$ ) and $\mathrm{dppBz}(10 \mathrm{~mol} \%, 0.02 \mathrm{mmol})$ under air, followed by $\mathrm{Zn}$ ( 0.5 equiv, 0.1 $\mathrm{mmol}$ ). The mixture was evacuated and backfilled with $\mathrm{N}_{2}$ (three times). THF (2 $\mathrm{mL})$ was added then followed by LDA $(105 \mathrm{~mol} \%, 0.21 \mathrm{mmol})$ subsequently. The Schlenk tube was then sealed with a Teflon lined cap and put into a cooled bath $\left(-10^{\circ} \mathrm{C}\right)$. After stirring for $5 \mathrm{~min}$, bormdifluoroacetate $2 \mathrm{a}$ (3.0 equiv, $0.6 \mathrm{mmol}$ ) was added to the reaction mixture, and the Schlenk tube was then resealed with a Teflon lined cap and put back into the cooled bath $\left(-10^{\circ} \mathrm{C}\right)$. After stirring for another $12 \mathrm{~h}$, the reaction mixture was diluted with ethyl acetate $(5 \mathrm{~mL})$. The solvent was removed under reduced pressure, and the residue was purified by flash column chromatography on silica gel to give the desired product.

\section{Data availability}

The authors declare that all the data supporting the findings of this research are available within the article and its supplementary information.

Received: 3 August 2018 Accepted: 8 November 2018 Published online: 23 November 2018

\section{References}

1. Müller, K., Faeh, C. \& Diederich, F. Fluorine in pharmaceuticals: looking beyond intuition. Science 317, 1881-1886 (2007).

2. Mikami, K., Itoh, Y. \& Yamanaka, M. Fluorinated carbonyl and olefinic compounds: basic character and asymmetric catalytic reactions. Chem. Rev. 104, 1-16 (2004). 
3. Uneyama, K., Katagiri, T. \& Amii, H. a-trifluoromethylated carbanion synthons. Acc. Chem. Res. 41, 817-829 (2008).

4. Ma, J.-A. \& Cahard, D. Asymmetric fluorination, trifluoromethylation, and perfluoroalkylation reactions. Chem. Rev. 104, 6119-6146 (2004).

5. Zhang, C.-P., Chen, Q.-Y., Guo, Y., Xiao, J.-C. \& Gu, Y.-C. Progress in fluoroalkylation of organic compounds via sulfinatodehalogenation initiation system. Chem. Soc. Rev. 41, 4536-4559 (2012).

6. Liang, T., Neumann, C. N. \& Ritter, T. Introduction of fluorine and fluorinecontaining functional groups. Angew. Chem. Int. Ed. 52, 8214-8264 (2013).

7. Ni, C., Hu, M. \& Hu, J. Good partnership between sulfur and fluorine: sulfurbased fluorination and fluoroalkylation reagents for organic synthesis. Chem. Rev. 115, 765-825 (2015).

8. Belhomme, M.-C., Besset, T., Poisson, T. \& Pannecoucke, X. Recent progress toward the introduction of functionalized difluoromethylated building blocks onto $\mathrm{C}\left(\mathrm{sp}^{2}\right)$ and $\mathrm{C}(\mathrm{sp})$ centers. Chem. Eur. J. 21, 12836-12865 (2015).

9. Feng, Z., Xiao, Y.-L. \& Zhang, X. Transition-metal (Cu, Pd, Ni)-catalyzed difluoroalkylation via cross-coupling with difluoroalkyl halides. Acc. Chem. Res. 51, 2264-2278 (2018).

10. Nagib, D. A., Scott, M. E. \& MacMillan, D. W. C. Enantioselective $\alpha-$ trifluoromethylation of aldehydes via photoredox organocatalysis. J. Am. Chem. Soc. 131, 10875-10877 (2009).

11. Shibata, N., Mizuta, S. \& Kawai, H. Recent advances in enantioselective trifluoromethylation reactions. Tetrahedron.: Asymmetry 19, 2633-2644 (2008).

12. Cho, E. J. et al. The palladium-catalyzed trifluoromethylation of aryl chlorides. Science 328, 1679-1681 (2010).

13. Guo, C., Wang, R.-W. \& Qing, F.-L. Palladium catalyzed direct $\alpha$-arylation of a,a-difluoroketones with aryl bromides. J. Fluor. Chem. 143, 135-142 (2012).

14. Feng, Z., Min, Q.-Q., Xiao, Y.-L., Zhang, B. \& Zhang, X. Palladium-catalyzed difluoroalkylation of aryl boronic acids: a new method for the synthesis of aryldifluoromethylated phosphonates and carboxylic acid derivatives. Angew. Chem. Int. Ed. 53, 1669-1673 (2014)

15. Min, Q.-Q., Yin, Z., Feng, Z., Guo, W.-H. \& Zhang, X. Highly selective gemdifluoroallylation of organoborons with bromodifluoromethylated alkenes catalyzed by palladium. J. Am. Chem. Soc. 136, 1230-1233 (2014).

16. Shao, C., Shi, G., Zhang, Y., Pan, S. \& Guan, X. Palladium-catalyzed C-H ethoxycarbonyldifluoromethylation of electron-rich heteroarenes. Org. Lett. 17, 2652-2655 (2015).

17. Gu, Y., Leng, X. \& Sheng, Q. Cooperative dual palladium/silver catalyst for direct difluoromethylation of aryl bromides and iodides. Nat. Commun. 5, 5405-5411 (2014).

18. Feng, Z., Min, Q.-Q., Fu, X.-P., An, L. \& Zhang, X. Chlorodifluoromethanetriggered formation of difluoromethylated arenes catalysed by palladium. Nat. Chem. 9, 918-923 (2017).

19. Aikawa, K., Serizawa, H., Ishii, K. \& Mikami, K. Palladium-catalyzed Negishi cross-coupling reaction of aryl halides with (difluoromethyl)zinc reagent. Org. Lett. 18, 3690-3693 (2016).

20. Oishi, M., Kondo, H. \& Amii, H. Aromatic trifluoromethylation catalytic in copper. Chem. Commun. 45, 1909-1911 (2009).

21. Feng, Z., Chen, F. \& Zhang, X. Copper catalyzed cross-coupling of iodobenzoates with bromozinc-difluorophosphonate. Org. Lett. 14, 1938-1941 (2012).

22. Belhomme, M.-C., Poisson, T. \& Pannecoucke, X. Copper-catalyzed direct C-2 difluoromethylation of furans and benzofurans: access to $\mathrm{C}-2 \mathrm{CF}_{2} \mathrm{H}$ derivatives. J. Org. Chem. 79, 7205-7211 (2014).

23. Jiang, X., Chu, L. \& Qing, F.-L. Copper-mediated oxidative difluoromethylenation of aryl boronic acids with $a$ silyldifluoromethylphosphonates: a new method for aryldifluorophosphonates. New J. Chem. 37, 1736-1741 (2013).

24. Serizawa, H., Ishii, K., Aikawa, K. \& Mikami, K. Copper-catalyzed difluoromethylation of aryl iodides with (difluoromethyl)zinc reagent. $\mathrm{Org}$. Lett. 18, 3686-3689 (2016).

25. Gao, X., Xiao, Y.-L., Wan, X. \& Zhang, X. Copper-catalyzed highly stereoselective trifluoromethylation and difluoroalkylation of secondary propargyl sulfonates. Angew. Chem. Int. Ed. 57, 3187-3191 (2018).

26. Ivanova, M. V., Bayle, A., Besset, T., Poisson, T. \& Pannecoucke, X. Coppermediated formation of aryl, heteroaryl, vinyl and alkynyl difluoromethylphosphonates: a general approach to fluorinated phosphate mimics. Angew. Chem. Int. Ed. 54, 13406-13410 (2015).

27. Jiang, X., Chu, L. \& Qing, F.-L. Copper-mediated oxidative cross-coupling reaction of terminal alkynes with $\alpha$-silyldifluoromethylphosphonates: an efficient method for a,a-difluoropropargylphosphonates. Org. Lett. 14, 2870-2873 (2014).

28. Belhomme, M.-C., Poisson, T. \& Pannecoucke, X. Copper catalyzed $\beta$ difluoroacetylation of dihydropyrans and glycals by means of direct $\mathrm{C}-\mathrm{H}$ functionalization. Org. Lett. 15, 3428-3431 (2013).

29. Zhu, J., Ni, C., Gao, B. \& Hu, J. Copper(0)-mediated fluoroalkylation of iodobenzene with 2-bromo-1,1,2,2-tetrafluoroethyl compounds: investigation on the influence of $\mathrm{R}$ substituent on the reactivity of $\mathrm{RCF}_{2} \mathrm{Cu}$ species. J. Fluor. Chem. 171, 139-147 (2015).

30. He, Z. et al. Copper-mediated trifluoromethylation of propiolic acids: facile synthesis of a-trifluoromethyl ketones. Chem. Sci. 4, 3478-3483 (2013).

31. Qi, Q., Shen, Q. \& Lu, L. Copper-mediated aerobic fluoroalkylation of arylboronic acids with fluoroalkyl iodides at room temperature. J. Am. Chem. Soc. 134, 6548-6551 (2012).

32. Hu, M., Ni, C. \& Hu, J. Copper-mediated trifluoromethylation of a-diazo esters with $\mathrm{TMSCF}_{3}$ : the important role of water as a promoter. J. Am. Chem. Soc. 134, 15257-15260 (2012).

33. Moselage, M., Li, J. \& Ackermann, L. Cobalt-catalyzed C-H activation. ACS Catal. 6, 498-525 (2016).

34. Cahiez, G. \& Moyeux, A. Cobalt-catalyzed cross-coupling reactions. Chem. Rev. 110, 1435-1462 (2010).

35. Su, B., Cao, Z.-C. \& Shi, Z.-J. Exploration of earth-abundant transition metals $(\mathrm{Fe}, \mathrm{Co}$, and $\mathrm{Ni}$ ) as catalysts in unreactive chemical bond activations. Acc. Chem. Res. 48, 886-896 (2015).

36. Liang, Y. \& Fu, G. C. Catalytic asymmetric synthesis of tertiary alkyl fluorides: Negishi cross-couplings of racemic a,a-dihaloketones. J. Am. Chem. Soc. 136, 5520-5524 (2016).

37. Jiang, X., Sakthivel, S., Kulbitski, K., Nisnevich, G. \& Gandelman, M. Efficient synthesis of secondary alkyl fluorides via suzuki cross-coupling reaction of 1Halo-1-fluoroalkanes. J. Am. Chem. Soc. 136, 9548-9551 (2014).

38. Su, Y.-M., Feng, G.-S., Wang, Z.-Y., Lan, Q. \& Wang, X.-S. Nickel-catalyzed monofluoromethylation of aryl boronic acids. Angew. Chem. Int. Ed. 54, 6003-6007 (2015).

39. Schwaebe, M. K., McCarthy, J. R. \& Whitten, J. P. Nickel(0)-catalyzed coupling of vinylzirconiums to $\alpha$-bromo- $\alpha, \alpha$-difluoro esters Convenient generation of a functionalized allyldifluoro moiety. Tetrahedron Lett. 41, 791-794 (2000).

40. Sheng, J., Ni, H.-Q., Liu, G., Li, Y. \& Wang, X.-S. Combinatorial nickelcatalyzed monofluoroalkylation of aryl boronic acids with unactivated fluoroalkyl iodides. Org. Lett. 19, 4480-4483 (2017).

41. Sheng, J., Ni, H.-Q., Zhang, H.-R., Wang, Y.-N. \& Wang, X.-S. Nickelcatalyzed reductive cross-coupling of aryl halides with monofluoroalkyl halides for late-stage monofluoroalkylation. Angew. Chem. Int. Ed. 57, 7634-7639 (2018).

42. Gu, J.-W., Min, Q.-Q., Yu, L.-C. \& Zhang, X. Tandem difluoroalkylationarylation of enamides catalyzed by nickel. Angew. Chem. Int. Ed. 55, 12270-12274 (2016)

43. Xiao, Y.-L., Guo, W.-H., He, G.-Z., Pan, Q. \& Zhang, X. Nickel-catalyzed cross-coupling of functionalized difluoromethyl bromides and chlorides with aryl boronic acids: a general method for difluoroalkylated arenes. Angew. Chem. Int. Ed. 53, 9909-9913 (2014).

44. $\mathrm{Xu}, \mathrm{C}$. et al. Difluoromethylation of (hetero)aryl chlorides with chlorodifluoromethane catalyzed by nickel. Nat. Commun. 9, 1170-1179 (2018)

45. An, L., Xiao, Y.-L., Zhang, S. \& Zhang, X. Bulky diamine ligand promotes cross-coupling of difluoroalkyl bromides by iron catalysis. Angew. Chem. Int. Ed. 57, 6921-6925 (2018).

46. Lin, X., Zheng, F. \& Qing, F.-L. Iron-catalyzed cross-coupling reactions between arylzinc reagents and alkyl halides bearing $\beta$-fluorines. Organometallics 31, 1578-1582 (2012).

47. Miao, W. et al. Iron-catalyzed difluoromethylation of arylzincs with difluoromethyl 2-pyridyl sulfone. J. Am. Chem. Soc. 140, 880-883 (2018).

48. Ohtsuka, Y. \& Yamakawa, T. Direct ethoxycarbonyldifluoromethylation of aromatic compounds using Fenton reagent. Tetrahedron 67, 2323-2331 (2011).

49. Araki, K. \& Inoue, M. Cobalt-catalyzed cross-coupling reaction of arylzinc reagents with ethyl bromodifluoroacetate. Tetrahedron 69, 3913-3918 (2013).

50. Ohtsuka, Y. \& Yamakawa, T. Cobalt/diamine-catalyzed 1,1-difluoroethylation and 2,2,2-trifluoroethylation of aryl Grignard reagents with corresponding fluoroalkyl halides. J. Fluor. Chem. 185, 96-102 (2016).

51. Chou, T. S. et al. Stereospecific synthesis of 2-deoxy-2,2-difluororibonolactone and its use in the preparation of $2^{\prime}$-Deoxy- $2^{\prime}, 2^{\prime}$-difluoro- $\beta$-D-ribofuranosyl pyrimidine nucleosides: the key role of selective crystallization. Synthesis $\mathbf{6}$, 565-570 (1992).

52. Yue, X., Qiu, X.-L. \& Qing, F.-L. Synthesis of $2^{\prime}, 3^{\prime}$-dideoxy-6',6'-difluoro-3' azanucleosides. J. Fluor. Chem. 129, 866-874 (2008).

53. Nakayama, K. et al. Synthesis and antifungal activity of rhodopeptin analogues. 2. Modification of the west amino acid moiety. Org. Lett. 2, 977-980 (2000)

54. Uoto, K. et al. Synthesis and structure-activity relationships of novel 2',2'difluoro analogues of docetaxel. Chem. Pharm. Bull. 45, 1793-1804 (1997).

55. Fujikawa, K., Fujioka, Y., Kobayashi, A. \& Amii, H. A new method for aromatic difluoromethylation: copper-catalyzed cross-coupling and decarboxylation sequence from aryl iodides. Org. Lett. 13, 5560-5563 (2011).

56. Ge, S., Arlow, S. I., Mormino, M. G. \& Hartwig, J. F. Pd-catalyzed $\alpha$-arylation of trimethylsilyl enolates of a,a-difluoroacetamides. J. Am. Chem. Soc. 136, 14401-14404 (2014). 
57. Xu, L. \& Vicic, D. A. Direct difluoromethylation of aryl halides via base metal catalysis at room temperature. J. Am. Chem. Soc. 138, 2536-2539 (2016).

58. Aikawa, K., Maruyama, K., Nitta, J., Hashimoto, R. \& Mikami, K. Siladifluoromethylation and difluoromethylation onto $\mathrm{C}\left(\mathrm{sp}^{3}\right), \mathrm{C}\left(\mathrm{sp}^{2}\right)$, and $\mathrm{C}$ (sp) centers using ruppert-prakash reagent and fluoroform. Org. Lett. 18, 3354-3357 (2016).

59. An, L., Xu, C. \& Zhang, X. Highly selective nickel-catalyzed gemdifluoropropargylation of unactivated alkylzinc reagents. Nat. Commun. 8, 1460-1468 (2017).

60. Cinderella, A. P., Vulovic, B. \& Watson, D. A. Palladium-catalyzed crosscoupling of silyl electrophiles with alkylzinc halides: a Silyl-Negishi reaction. J. Am. Chem. Soc. 139, 7741-7744 (2017).

61. Luo, Z. et al. Synthesis and evaluation of multi-target-directed ligands against Alzheimer's disease based on the fusion of donepezil and ebselen. J. Med. Chem. 56, 9089-9099 (2013).

62. Chen, Q.-A., Kim, D. K. \& Dong, V. M. Regioselective hydroacylation of 1,3Dienes by cobalt catalysis. J. Am. Chem. Soc. 136, 3772-3775 (2014).

63. Liebeskind, L. S., Baysdon, S. L., South, M. S., Iyer, S. \& Leeds, J. P. The development of an organotransition metal synthesis of quinones. Tetrahedron 41, 5839-5853 (1985).

64. Fillon, H., Gosmini, C. \& Périchon, J. New chemical synthesis of functionalized arylzinc compounds from aromatic or thienyl bromides under mild conditions using a simple cobalt catalyst and zinc dust. J. Am. Chem. Soc. 125, 3867-3870 (2003).

65. Jin, M.-Y. \& Yoshikai, N. Cobalt-Xantphos-catalyzed, LiCl-mediated preparation of arylzinc reagents from aryl iodides, bromides, and chlorides. $J$. Org. Chem. 76, 1972-1978 (2011).

66. Brennan, M. R., Kim, D. \& Fout, A. R. A synthetic and mechanistic investigation into the cobalt(I) catalyzed amination of aryl halides. Chem. Sci. 5, 4831-4839 (2014).

\section{Acknowledgements}

We gratefully acknowledge the Strategic Priority Research Program of the Chinese Academy of Sciences (Grant No. XDB20000000), the National Basic Research Program of China (973 Program 2015CB856600), the National Science Foundation of China

$(21772187,21522208)$ for financial support.

\section{Author contributions}

C.L. and Y.-X.C. designed and performed the experiments. R.W., Y.-N.W., and Q.L. helped to complete the experiments. X.-S.W. directed the project and wrote the manuscript. All authors interpreted the results on the manuscript.

\section{Additional information}

Supplementary Information accompanies this paper at https://doi.org/10.1038/s41467018-07525-y.

Competing interests: The authors declare no competing interests.

Reprints and permission information is available online at http://npg.nature.com/ reprintsandpermissions/

Publisher's note: Springer Nature remains neutral with regard to jurisdictional claims in published maps and institutional affiliations.

\section{(c) (i)}

Open Access This article is licensed under a Creative Commons Attribution 4.0 International License, which permits use, sharing, adaptation, distribution and reproduction in any medium or format, as long as you give appropriate credit to the original author(s) and the source, provide a link to the Creative Commons license, and indicate if changes were made. The images or other third party material in this article are included in the article's Creative Commons license, unless indicated otherwise in a credit line to the material. If material is not included in the article's Creative Commons license and your intended use is not permitted by statutory regulation or exceeds the permitted use, you will need to obtain permission directly from the copyright holder. To view a copy of this license, visit http://creativecommons.org/ licenses/by/4.0/.

(C) The Author(s) 2018 